\title{
Destruction of tumor vasculature and abated tumor growth upon VEGF blockade is driven by proapoptotic protein Bim in endothelial cells
}

\author{
Edwina Naik, ${ }^{1,2}$ Lorraine A. O’Reilly, ${ }^{1}$ Marie-Liesse Asselin-Labat, ${ }^{1,2}$ \\ Delphine Merino, ${ }^{1}$ Ann Lin, ${ }^{1}$ Michele Cook, ${ }^{1}$ Leigh Coultas, ${ }^{1,2}$ \\ Philippe Bouillet, ${ }^{1,2}$ Jerry M. Adams, ${ }^{1,2}$ and Andreas Strasser ${ }^{1,2}$
}

TThe Walter and Eliza Hall Institute of Medical Research, Parkville, Melbourne, Victoria 3052, Australia

2Department of Medical Biology, The University of Melbourne, Melbourne, Victoria 3010, Australia
CORRESPONDENCE

Andreas Strasser:

strasser@wehi.edu.au

Abbreviations used: EC, endothelial cell; GCV, ganciclovir; LLC, Lewis lung carcinoma; MMTV-PyMT, mouse mammary tumor virus-polyomavirus transgene; NGS, normal goat serum; PI, propidium iodide; TK, thymidine kinase; VEGF, vascular endothelial growth factor; vWF, von Willebrand factor.

\section{To expand substantially and spread malignantly, a cancer must induce the formation of new blood vessels (Bergers and Benjamin, 2003; Ferrara et al., 2004). In the pivotal angiogenic switch, the tumor acquires the ability to produce or increase the bioavailability of vascular endothe- lial growth factor (VEGF-A; herein referred to as VEGF), which is essential for endothelial cell (EC) growth and survival in the tumor vascula- ture (Bergers and Benjamin, 2003; Ferrara et al., 2004). Novel anticancer agents such as bevaci- zumab, a humanized $\mathrm{mAb}$ against VEGF, that block VEGF signaling and trigger EC apoptosis and vascular regression have been approved for use in several advanced malignancies (Ellis and Hicklin, 2008). Despite the considerable poten- tial of targeting the neovasculature in cancer therapy, the clinical responses to VEGF block- ade have often been modest, and a better under- standing of the underlying mechanisms is clearly needed.}

E. Naik's present address is Genentech, South San Francisco, CA 94080 .
Although VEGF blockade is known to kill ECs within the blood vessels of solid tumors, how the ECs die has been unknown. Because the prosurvival protein $\mathrm{Bcl}-2$ is up-regulated in ECs after stimulation with VEGF (Gerber et al., 1998), we reasoned that a proapoptotic BH3 (Bcl-2 homology 3)-only member of that family (Youle and Strasser, 2008) might initiate the EC death provoked by falling VEGF levels when solid tumors shrink during cancer therapy. The BH3-only protein Bim (O'Connor et al., 1998) is critical for the apoptosis induced by cytokine deprivation in several cell types (Bouillet et al., 1999; Youle and Strasser, 2008), and notably, in early development of the eye, Bim is critical for the programmed cell death of the ECs comprising the vessels of the tunica vasculosa lentis, a residual embryonic vasculature (unpublished data). We therefore hypothesized

2011 Naik et al. This article is distributed under the terms of an AttributionNoncommercial-Share Alike-No Mirror Sites license for the first six months after the publication date (see http://www.rupress.org/terms). After six months it is available under a Creative Commons License (Attribution-Noncommercial-Share Alike 3.0 Unported license, as described at http://creativecommons.org/licenses/ by-nc-sa/3.0/). 
that Bim might be responsible for the EC death that is induced by deprivation or blockade of VEGF in tumor-associated blood vessels.

\section{RESULTS AND DISCUSSION \\ Novel experimental system to examine the impact of tumor shrinkage and the resulting VEGF reduction on tumor vasculature}

We wanted first to explore whether the tumor shrinkage that accompanies chemotherapy impairs the tumor vasculature. However, conventional anticancer drugs can complicate studies of the relationship between the tumor and its vasculature by directly killing the ECs (Miller et al., 2001). Thus, we developed an experimental system that reveals how tumor shrinkage affects ECs in the absence of direct toxicity to the tumor vasculature. Mouse B16.F1 melanoma and 3LL-Lewis lung carcinoma (LLC) cells were rendered sensitive to the otherwise nontoxic prodrug ganciclovir (GCV) by introduction of a vector allowing expression of a hyperactive form of thymidine kinase (TK; Black et al., 2001). After confirmation of their sensitivity to GCV in vitro (Fig. S1, A-C), these cells were injected subcutaneously into syngeneic WT or Bim ${ }^{-1-}$ mice to establish solid tumors. In these animals, GCV treatment should only directly kill the tumor cells.

We first assessed how tumor shrinkage affected VEGF levels. Three daily injections of GCV produced a comparable drop in B16.F1 tumor weight in WT and Bim ${ }^{-1-}$ mice (Fig. S1 D). Daily examinations showed that the reduction in the intratumoral levels of VEGF within GCV-treated tumors coincided with the reduction in tumor growth and tumor volume (Fig. S1, $\mathrm{E}$ and $\mathrm{F}$ ). This is consistent with the notion that the B16.F1 cancer cells are major producers of VEGF within the tumors. Fractionation of nontumor $\left(\mathrm{GFP}^{-}\right)$and tumor cell populations $\left(\mathrm{GFP}^{+}\right)$confirmed that both populations expressed appreciable levels of VEGF (Fig. S1 G). However, as tumor cells comprise the bulk of the tumor mass, tumor cell-specific killing mediated by GCV should account for most of the reduction in intratumoral VEGF levels. $\mathrm{VEGF}_{120}$ and $\mathrm{VEGF}_{164}$ isoforms predominate in both mouse and human tumors (Ferrara et al., 1991), and it was revealed that in the majority of GCVtreated B16.F1 tumors, at least one of these VEGF isoforms was substantially reduced (Fig. 1 A). Indeed, ELISA readings confirmed that GCV treatment provoked a precipitous drop in intratumoral VEGF levels: 91\% in WT and 85\% in $\mathrm{Bim}^{-1-}$ animals (Fig. 1 B). Accordingly, immunohistochemical staining of B16.F1 tumors showed that the GCV-induced tumor shrinkage led to large areas devoid of VEGF (Fig. $1 \mathrm{C}$ ).

\section{Bim drives the EC apoptosis evoked by the drop in VEGF levels}

Because the tumor vasculature in these animals is host derived, comparison of tumors grown in Bim-deficient and WT mice allowed us to determine whether the destruction of the tumor vasculature relies on Bim. Importantly, in the Bim-deficient hosts, the loss of tumor vasculature and EC apoptosis was markedly reduced, as assessed by both analysis of microvessel density (Hasan et al., 2002) and flow cytometry using CD31 as a marker of ECs. As CD31 is also expressed on a small subset of leukocytes, we sought to confirm the identity of the CD31+ structures in our microvessel density analysis (Fig. 2, A and B). Immunolabeling for both F4/80 (macrophages) and von Willebrand factor (vWF; ECs) revealed that macrophage infiltrate was minimal and that $\mathrm{vWF}^{+}$ECs coalesced to form luminal structures consistent with blood vessels and identical to that observed with
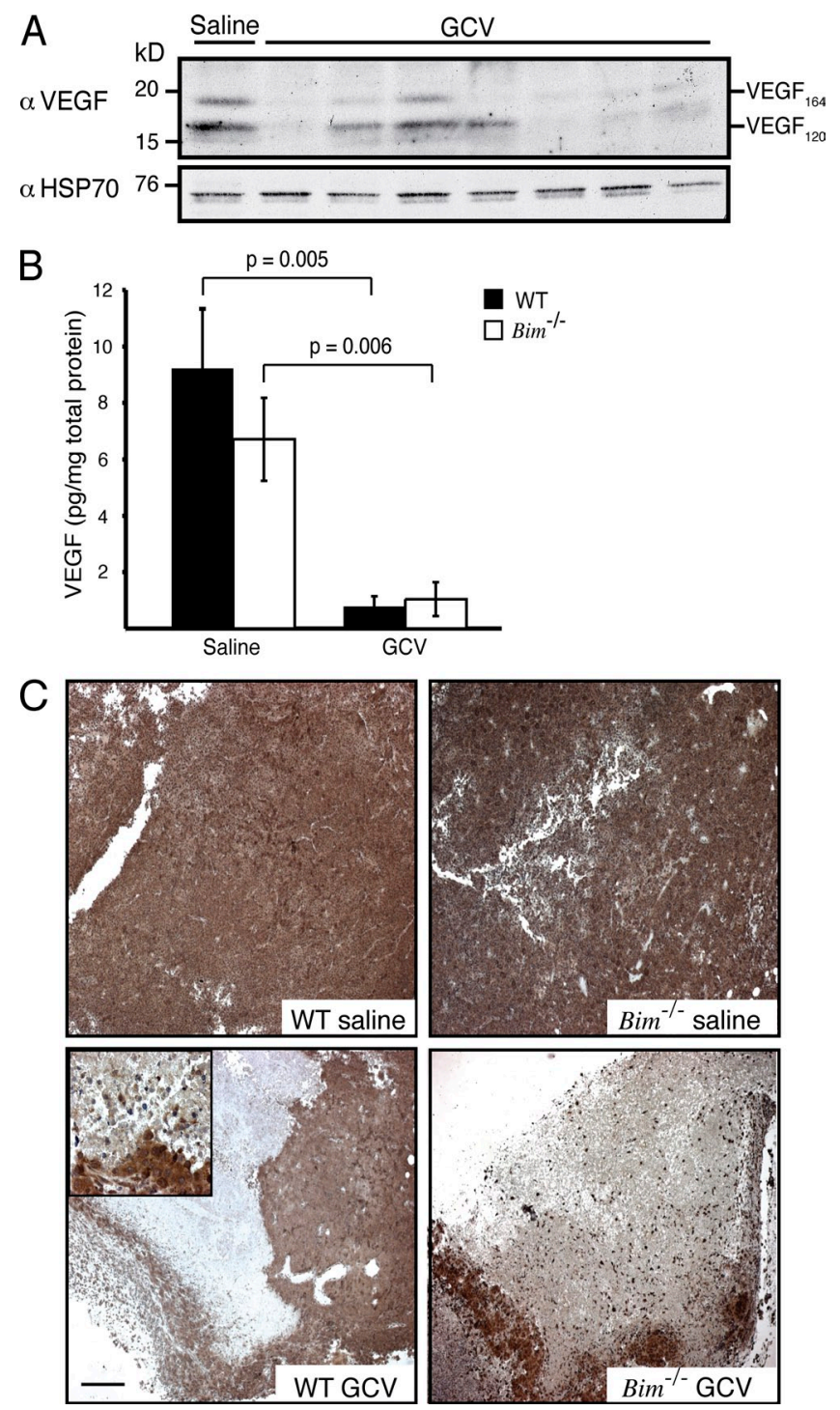

Figure 1. GCV treatment reduces VEGF expression in B16.F1 tumors. (A) Western blot analysis of the expression of the two predominant isoforms of tumor-associated VEGF in homogenates of TK-expressing B16.F1 melanomas generated from tumors grown in WT mice treated with three daily injections of GCV and harvested on day 4. (B) VEGF ELISA performed on lysates from B16.F1 tumors treated as in A. Data represent mean \pm SEM of five independent mice per genotype and treatment condition. (C) Representative photomicrographs of B16.F1 tumors treated as in A. Inset shows magnification of the boundary of VEGF-expressing and non-expressing tumor cells. Bar, $200 \mu \mathrm{m}$. 
CD31 staining (Fig. S2 A). As anticipated, there was little overlap between the localization of $\mathrm{F} 4 / 80^{+}$and $\mathrm{vWF}^{+}$immunoreactivity, indicating that few macrophages were associated with blood vessels. Consistent with these data, the vast majority of $\mathrm{F} 4 / 80^{+}$cells (ranging between 73 and $86 \%$ for all tumors and treatment conditions) did not express CD31 (Fig. S2 B). Thus, the CD31 ${ }^{+}$structures identified by immunohistochemistry and the $\mathrm{CD} 31^{+}$cells detected by flow cytometry represent ECs. In WT mice, the GCV-treated tumors exhibited fewer CD31+ vessels than the controls (Fig. 2, A and B) and accordingly contained more large areas of necrosis (Fig. 2 A). In contrast, the tumors in GCV-treated $\mathrm{Bim}^{-1-}$ mice maintained significantly greater vascularity (Fig. 2 B); thus, their vascular architecture was preserved, and they had fewer necrotic areas (Fig. 2 A). Notably, the
GCV-induced tumor shrinkage caused an $\sim 50 \%$ loss in viable tumor-associated ECs $\left(\mathrm{CD} 31^{+}\right.$propidium iodide ${ }^{-}$ $\left.\left[\mathrm{CD} 31^{+} \mathrm{PI}^{-}\right]\right)$in WT mice $(\mathrm{P}=0.01)$, whereas the corresponding tumors from $\mathrm{Bim}^{-1-}$ mice exhibited no such depletion (Fig. 2 C). This effect appears to be specific for the proapoptotic activity of Bim, as tumors from GCV-treated mice lacking the BH3-only protein Bmf, which like Bim has been implicated in the apoptosis induced in certain cell types by growth factor deprivation (Labi et al., 2008), exhibited numbers of viable ECs comparable with WT controls (Fig. S3).

We inferred from these results that Bim was required for EC apoptosis during tumor regression. Indeed, combined staining for CD31 and DNA double-strand breaks (TUNEL), a hallmark of apoptosis, identified abundant dying ECs in
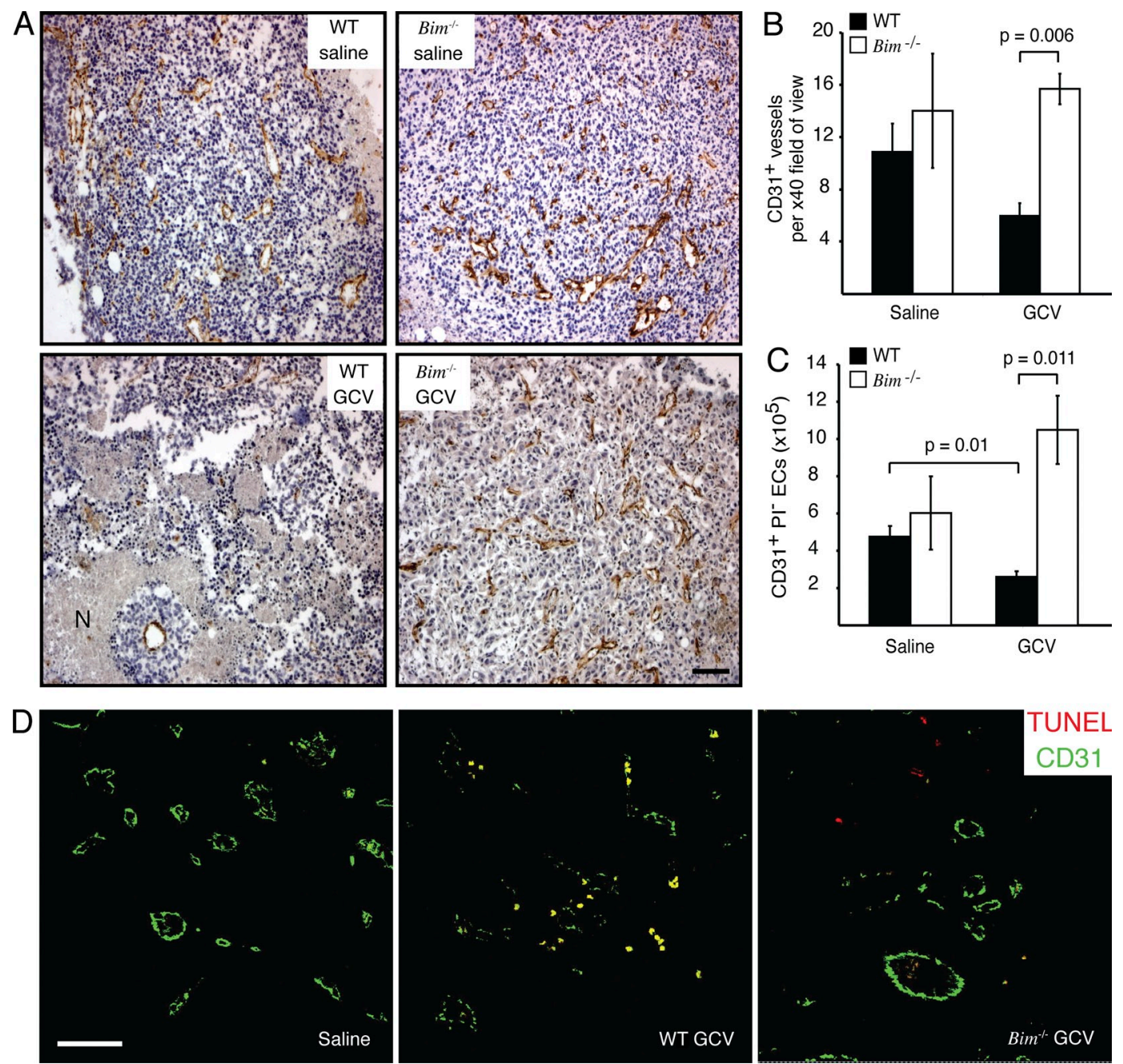

Figure 2. Bim is required for the tumor shrinkage-induced apoptosis of tumor-associated ECs. (A) TK-expressing B16.F1 melanomas were grown subcutaneously in WT or Bim-1- mice until they reached a volume of $\sim 50 \mathrm{~mm}^{3}$, whereupon the animals were treated with three daily injections of GCV or saline. On day 4, sections of tumors were stained for CD31 (brown). N, necrosis. (B) Quantification of microvessel density in tumor tissue sections described in A. Data represent the mean \pm SEM ( $n=4$ per genotype and treatment condition). (C) FACS analysis of single-cell suspensions of tumors from saline- or GCV-treated WT or Bim ${ }^{-1-}$ mice. Data represent the mean \pm SEM ( $n=5$ per genotype and treatment condition). (D) Tumors were subjected to TUNEL and CD31 staining to identify apoptotic ECs (yellow). Bars: (A) $100 \mu \mathrm{m}$; (D) $40 \mu \mathrm{m}$. 
GCV-treated tumors from WT animals but few in equivalent tumors from $\mathrm{Bim}^{-/-}$animals (Fig. $\left.2 \mathrm{D}\right)$. In support of the results from the melanoma tumor model, experiments with the lung carcinoma cells confirmed that Bim is essential for the intratumoral EC apoptosis provoked by the drop in VEGF levels elicited by GCV treatment (Fig. S4).

To monitor Bim expression in tumor-associated ECs, we exploited Bim-lac $Z$ (heterozygous) knockin mice, in which a $\beta$-galactosidase transcriptional reporter replaces the Bim coding region (Bouillet et al., 2001). Flow cytometric analysis of cells stained for CD31 and incubated with a fluorogenic $\beta$-galactosidase substrate revealed that cells with high Bim transcription increased several-fold and peaked after two daily injections of GCV (on harvest day 3; Fig. 3, A and B), probably because the ECs with elevated Bim were then rapidly eliminated. To facilitate protein analysis, CD $31^{+}$ECs were isolated from saline- or GCV-treated B16.F1 tumors, and their purity was confirmed (Fig. S5, A-C). The level of Bim $\mathrm{EL}_{\mathrm{L}}$, the most highly expressed isoform of Bim in the majority of tissues (O'Connor at al., 1998; O’Reilly et al., 2000), was 2.4fold higher in ECs from GCV-treated than saline-treated tumors (Fig. $3 \mathrm{C}$ and Fig. S5 F).

Bim levels are regulated in multiple ways (Ley et al., 2005; Youle and Strasser, 2008), and pertinently, several proteins implicated in its regulation were altered in tumorassociated ECs after GCV treatment. The phosphorylated (active) forms of Akt and Erk1/2 were reduced (Fig. S5, $\mathrm{D}$ and $\mathrm{E}$ ), and the reduced level of the phosphorylated (inactive) form of FOXO3a (Fig. S5 D) is consistent with the activation and nuclear translocation of this transcription factor, which induces Bim transcription after cytokine withdrawal (Dijkers et al., 2000).

\section{Bim-mediated EC death is essential for VEGF} blockade-induced inhibition of tumor growth

To causally link VEGF neutralization, Bim up-regulation, and EC apoptosis, we treated 3LL-LLC-bearing animals with VEGF-blocking mAbs (Liang et al., 2006). As with GCVinduced tumor shrinkage, direct VEGF blockade in WT mice substantially reduced both vascularization (Fig. $4 \mathrm{~A}$ ) and the number of tumor-associated ECs (Fig. 4 B). In contrast, neither vessel density nor ECs decreased in the tumors of $\mathrm{Bim}^{-1-}$ mice (Fig. 4, A and B). Moreover, apoptotic ECs (Fig. $4 \mathrm{D}$, dashed boxes) were prevalent in the carcinomas from WT animals treated with anti-VEGF antibody but scarce in those tumors from $\mathrm{Bim}^{-/-}$mice. Like the GCV treatment of mice bearing TK-expressing tumors, VEGF blockade augmented Bim expression. The proportion of tumor-associated ECs with elevated Bim transcription increased significantly after anti-VEGF antibody treatment of both the lung carcinoma and melanoma (Fig. $4 \mathrm{C}$ and not depicted). Notably, 3LL-LLC-bearing mice lacking the $\mathrm{BH} 3$-only proteins Puma or Bid did not exhibit any significant protection of ECs after anti-VEGF treatment (Fig. 4 E). Thus, Bim is the principal initiator of this apoptotic response in ECs.

As observed with other tumors (Liang et al., 2006), VEGF blockade significantly slowed the growth of the 3LL-LLC in WT mice (Fig. 4 F). In striking contrast, the tumors in antiVEGF antibody-treated $\mathrm{Bim}^{-1-}$ mice grew much faster, indeed at rates comparable with those in control IgG-treated $\mathrm{Bim}^{-1-}$ or WT animals (Fig. 4 F). To exclude the possibility that loss of the proapoptotic function of Bim in hematopoietic cells (Bouillet et al., 1999) might have impacted the response of tumors to VEGF blockade in $\mathrm{Bim}^{-/-}$mice, we performed reciprocal hematopoietic reconstitutions (with reconstitution efficiency $>85 \%$; unpublished data) and evaluated the response
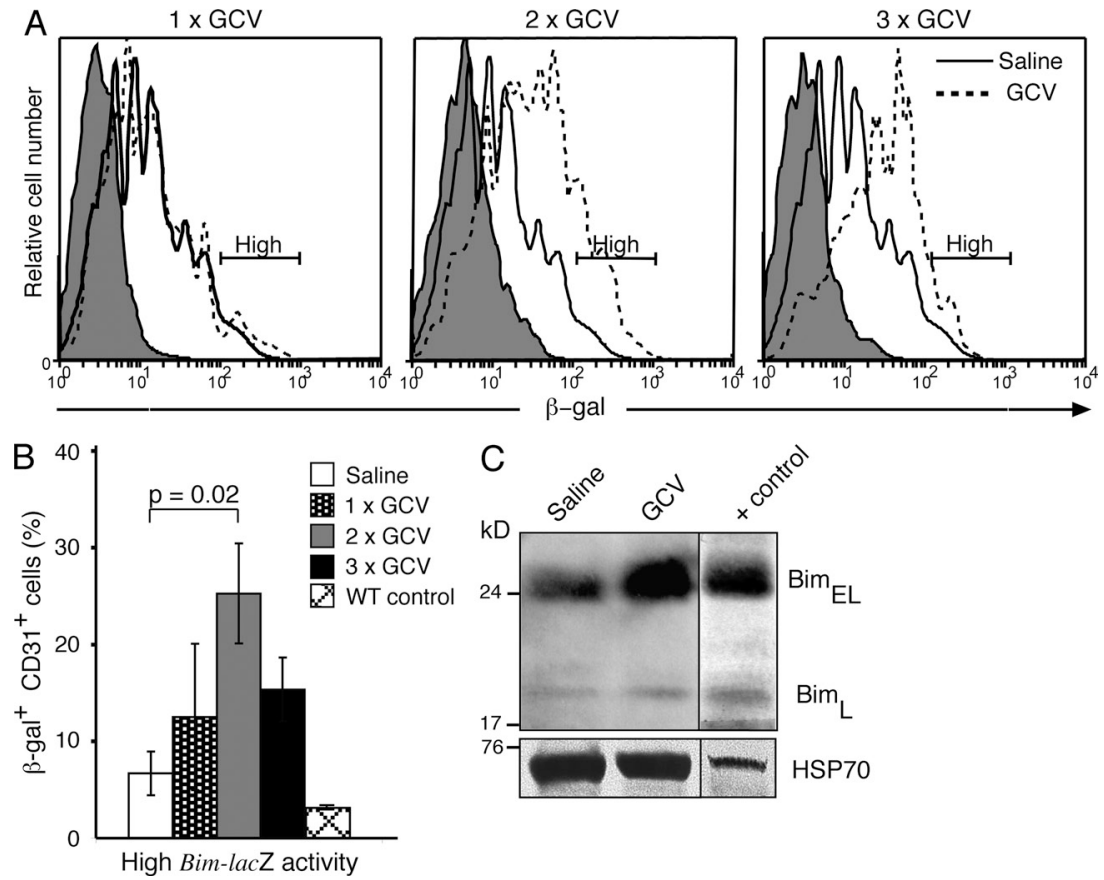

Figure 3. Drug-induced tumor shrinkage causes up-regulation of a Bim transcriptional reporter and elevated Bim protein in tumor-associated ECs. TK-expressing B16.F1 melanomas were grown and treated as described in Generation of B16.F1 and 3LL-LLC cell lines stably expressing TK-SR39 TK.

(A) Representative histograms depict EC populations with high $\beta$-galactosidase ( $\beta$-gal) activity. Solid lines depict $\beta$-galactosidase activity in ECs from salinetreated tumors, dashed lines depict $\beta$-galactosidase activity in ECs from GCV-treated tumors, and closed regions represent a no-FDG negative control. (B) Bar graph depicting the percentages of tumor-associated ECs with high levels of $\beta$-galactosidase activity. Data represent the mean \pm SEM ( $n=3-5$ for both saline and GCV treatments). (C) Tumor-associated ECs were purified from $>10$ WT mice treated twice with saline or GCV and assessed for Bim expression. HSP70 served as a loading control, and the lysate from an E $\mu$-myc lymphoma served as a positive (+) control. Black lines indicate that intervening lanes have been spliced out. 


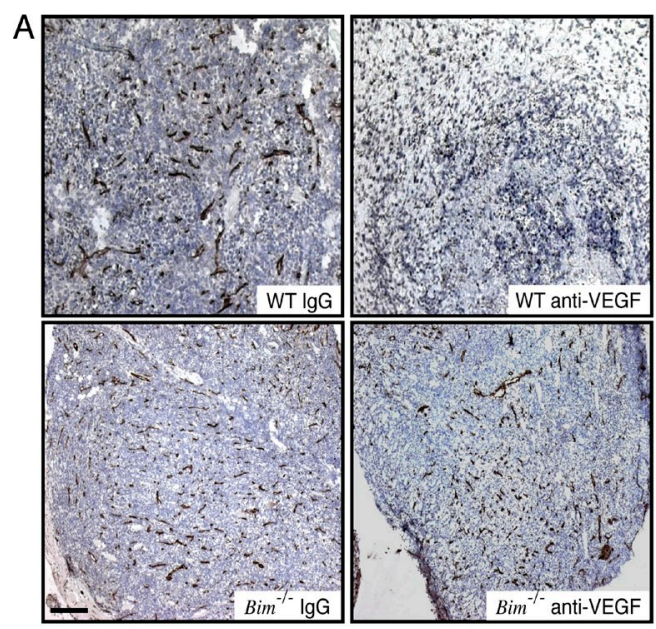

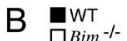

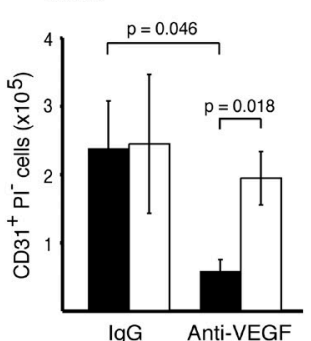

IgG Anti-VEGF

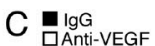

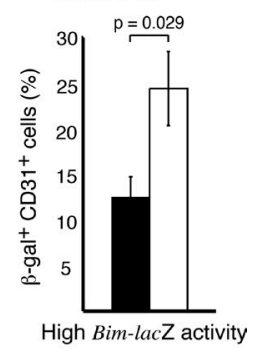

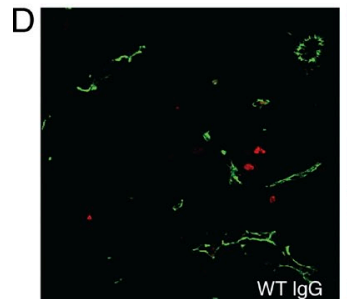
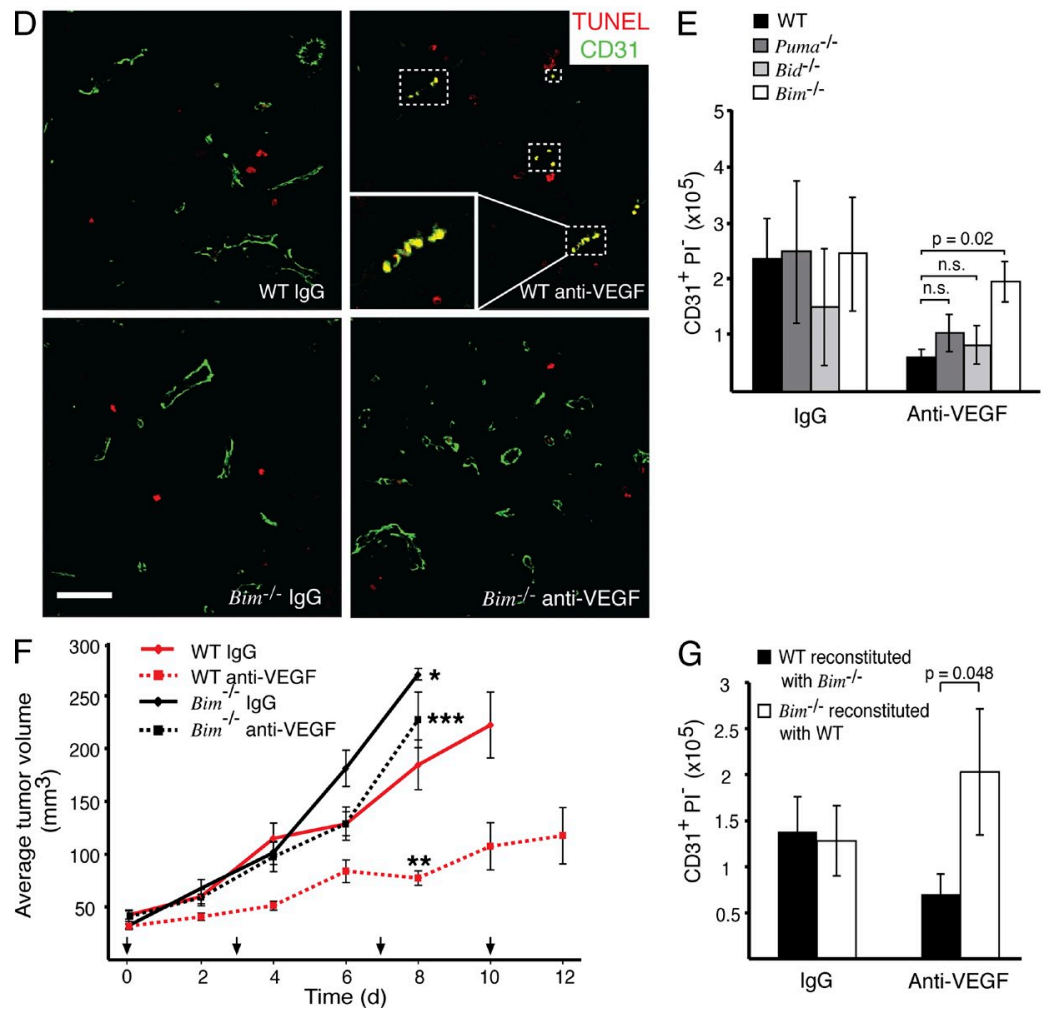

Figure 4. Bim is required for the death of tumor-associated ECs and inhibition of tumor growth on VEGF neutralization. (A) WT or Bim ${ }^{-1-}$ mice bearing subcutaneous 3 LL-LLCs were treated with anti-VEGF antibody or a control lg isotype-matched antibody when the tumors reached a volume of $\sim 50 \mathrm{~mm}^{3}$. CD31 immunohistochemistry revealed tumor vascularization at day 6 of treatment. (B) FACS analysis was used to enumerate viable tumor-associated ECs. Data represent mean \pm SEM ( $n=5-7$ for each treatment and genotype). (C) Bar graph depicts the percentages of tumor-associated ECs with high levels of $\beta$-galactosidase ( $\beta$-gal) activity. Mice were treated with two daily injections of control lgG or anti-VEGF antibody and analyzed $1 \mathrm{~d}$ after cessation of treatment. Data represent the mean \pm SEM $(n=3-5$ for both control Ig and anti-VEGF treatments). (D) Day 6 tumors from saline- or anti-VEGF antibody-treated WT or Bim $^{-1}$ - mice were subjected to TUNEL and CD31 staining. Inset shows magnification of a boxed region showing an apoptotic EC (yellow). Boxes highlight regions containing apoptotic ECs. Bars: (A) $200 \mu \mathrm{m}$; (D) $40 \mu \mathrm{m}$. (E) WT, Bim ${ }^{-1-}$, Bid $^{-1-}$, and Puma ${ }^{-1-}$ mice bearing 3LL-LLC were treated with anti-VEGF neutralizing antibody as described in Mice, expression constructs, and tumor models. FACS analysis was used to enumerate viable tumor-associated ECs. Data represent mean \pm SEM $(n=3-5$ for each treatment and genotype of mice). The data for WT and $\mathrm{Bim}^{-1-}$ mice are the same as those shown in B and are reproduced in this panel to facilitate comparison. n.S., not significant. (F) The growth of 3 LL-LLC in WT or $\mathrm{Bim}^{-1-}$ mice treated with VEGF neutralizing antibody or a control Ig antibody. Mice were sacrificed when tumors exceeded a diameter of $1 \mathrm{~cm}$ on any orthogonal parameter. Data represent mean tumor volume and SEs $\left(n=5-17\right.$ per time point and genotype of mice; ${ }^{*}, \mathrm{P}=0.047$ control lg-treated Bim ${ }^{-1-}$ mice vs. control lg-treated WT mice; ${ }^{* *}, P=0.0002$ anti-VEGF antibody-treated WT mice vs. control lg-treated WT mice; ${ }^{* *}, P=0.0001$ anti-VEGF-treated Bim ${ }^{-1-}$ mice vs. anti-VEGF antibodytreated WT mice). All statistical comparisons were made at day 8 of treatment. Arrows designate the days of treatment. (G) WT CD45.1 $1^{+}$(closed bars) or Bim ${ }^{-1-}$ CD45.2 $2^{+}$ (open bars) recipient mice were reconstituted with unfractionated bone marrow from Bim ${ }^{-1-}$ CD45.2+ or WT CD45.1+ donors, respectively. The hematopoietic compartment was reconstituted for $8 \mathrm{wk}$ before inoculation of 3 LL-LLC cells, and mice were subjected to treatment as described in Mice, expression constructs, and tumor models. FACS analysis was used to enumerate viable tumor-associated ECs. Data represent mean \pm SEM ( $n=4-13$ for each treatment and genotype of mice). 
of tumors grown in these chimeric mice to anti-VEGF antibody treatment. The numbers of viable tumor-associated ECs were reduced if the ECs were WT, as in the WT mice reconstituted with $\mathrm{Bim}^{-1-}$ bone marrow, but not if the ECs lacked Bim, as in $\mathrm{Bim}^{-1-}$ mice reconstituted with a WT hematopoietic system (Fig. $4 \mathrm{G}$ ). This indicates that the presence of a $\mathrm{Bim}^{-1-}$ hematopoietic compartment does not affect the response of tumor-associated ECs to VEGF blockade.

We also observed that Bim mediates the killing of intratumoral ECs after anti-VEGF antibody treatment in the mouse mammary tumor virus-polyomavirus transgene (MMTVPyMT) transgenic model of de novo mammary carcinogenesis. Injection of VEGF-neutralizing antibodies caused a significant reduction in the numbers of viable tumor-associated ECs in MMTV-PyMT transgenic WT mice (Fig. S6 A), which did not occur in the corresponding MMTV-PyMT transgenic $\mathrm{Bim}^{-1-}$ animals. Collectively, these results show that Bimmediated apoptosis of ECs is critical for the inhibition of tumor growth elicited by VEGF blockade.

\section{Key role of Bim in constraining tumor vasculature}

We have clarified in this study two issues regarding the relationship between the tumor and its vasculature. The first is whether the tumor shrinkage that accompanies cancer therapy destroys its vasculature. To avoid direct cytotoxic effects on ECs, we used a GCV-induced model of tumor regression and demonstrated that tumor shrinkage provoked a drop in intratumoral VEGF levels with consequent death of tumorassociated ECs and vascular destruction. Significantly, we established that the VEGF deprivation up-regulated the BH3-only protein Bim in the ECs and that Bim was responsible for their apoptosis in transplants of both a lung carcinoma and a melanoma, as well as in a de novo mammary carcinoma model. Consequently, it seems likely that many anticancer agents provoke damage to the tumor vasculature by up-regulating Bim in ECs.

The second issue is whether the tumor growth-inhibitory effects of agents that directly block VEGF signaling rely upon Bim-induced killing of intratumoral ECs. Indeed, Bim's killing activity within tumor-associated ECs proved to be essential for the tumor growth inhibitory activity of VEGF blockade. Diverse treatment modalities provoke EC apoptosis in solid tumors (Dhanabal et al., 1999; Park et al., 2005); thus, polymorphisms in genes that control EC apoptosis, such as BIM or its regulators, may affect the therapeutic responses of cancer patients.

Our results make it likely that new antiangiogenesis agents could be identified that act not by modulating VEGF-VEGF-R signaling directly, but instead by functioning downstream to increase the activity of Bim or, alternatively, that mimic its proapoptotic action by engaging multiple Bcl-2-like prosurvival molecules. Pertinently, small molecule mimetics of BH3-only proteins, such as ABT-737, have shown efficacy in preclinical solid tumor models (Oltersdorf et al., 2005; Cragg et al., 2007, 2008). Our findings indicate that their activity may be caused by not only direct killing of tumor cells but may in part also be mediated by their ability to trigger EC apoptosis. These considerations suggest that a multipronged attack on solid tumors and their vasculature might best be achieved by combining a VEGF blocker with a drug that inhibits an oncoprotein that maintains the tumor growth (e.g., an epithelial growth factor receptor tyrosine kinase inhibitor for lung cancers with EGF-R gene mutations) and a $\mathrm{BH} 3$ mimetic, which may promote apoptosis in both the tumor and ECs (Fig. S6 B; Cragg et al., 2009).

\section{MATERIALS AND METHODS}

Mice, expression constructs, and tumor models. All animal experiments followed the guidelines of the Walter and Eliza Hall Institute of Medical Research Animals Ethics Committee. The generation of $\mathrm{Bim}^{-1-}$ mice (Bouillet et al., 1999), now backcrossed for $>20$ generations onto a C57BL/6 genetic background, and Bmf ${ }^{-1-}$ (Labi et al., 2008), Puma ${ }^{-/-}$(Villunger et al., 2003), and $\mathrm{Bid}^{-1-}$ (Kaufmann et al., 2007) mice, all generated on an inbred C57BL/6 background using C57BL/6-derived embryonic stem cells, has been described previously. MMTV-PyMT transgenic mice (Guy et al., 1992) were intercrossed with $\mathrm{Bim}^{-/-}$mice to generate MMTV-PyMT transgenic Bim ${ }^{-/-}$mice, which were compared with WT $\left(\mathrm{Bim}^{+/+}\right) \mathrm{MMTV}-$ PyMT transgenic controls. Parental B16.F1 melanoma and 3LL-LLC cell lines maintained in DME plus 10\% FCS (Bovigen) or MT-RPMI plus $10 \mathrm{mM}$ Hepes and 10\% FCS, respectively, were provided by M. Smyth (Peter MacCallum Cancer Centre, Melbourne, Victoria, Australia). Clonal derivatives were made expressing the mutant, hyperactive form of TK (herein referred to as TK-SR39 [Kokoris and Black, 2002]; see next section), and $5 \times 10^{5}$ TK-SR39-expressing B16.F1 or 3LL-LLC cells were injected subcutaneously into the flanks of syngeneic $\mathrm{C} 57 \mathrm{BL} / 6$ recipients. When tumors reached a volume of $\sim 50 \mathrm{~mm}^{3}$, treatment with GCV or anti-VEGF antibodies was initiated. Daily intraperitoneal injections of $50 \mathrm{mg} / \mathrm{kg} \mathrm{GCV}$ were administered to B16.F1 or 3LL-LLC-bearing animals for a period not exceeding $7 \mathrm{~d}$. For treatment efficacy experiments, $5 \mathrm{mg} / \mathrm{kg}$ anti-VEGF $\mathrm{mAb}$ G6-31 (Genentech) was administered to 3LL-LLC-bearing animals three times per week for a period not exceeding $21 \mathrm{~d}$. To determine tumor volume, we measured three mutually orthogonal parameters with microcalipers and used the formula $\mathrm{V}=\mathrm{w} \times 1 \times \mathrm{d} \times 0.52$. Mice had to be euthanized when tumors reached a diameter of $10 \mathrm{~mm}$.

Generation of B16.F1 and 3LL-LLC cell lines stably expressing TK-SR39 TK. $10 \mu \mathrm{g}$ plasmid DNA was linearized with ScaI, precipitated, and electroporated into $2.5 \times 10^{6}$ cells using the $240 \mathrm{~V} / 960 \mathrm{mFD}$ capacitance setting on a Gene Pulser (Bio-Rad Laboratories). Colonies were established by limiting dilution and screened on the basis of GFP expression to establish clonal cell lines. For the in vitro GCV sensitivity assay, $10^{5}$ cells were plated into 6-well tissue culture plates $24 \mathrm{~h}$ before the addition of GCV. Cell viability was determined by PI staining and FACS analysis.

Hematopoietic reconstitution. Ablation of the hematopoietic compartment was achieved by exposing mice to two doses of 5.5 Gy of $\gamma$ irradiation (from a ${ }^{60} \mathrm{Co}$ source) given $2 \mathrm{~h}$ apart. Mice were then reconstituted by intravenous injection of a minimum of $2 \times 10^{6}$ viable, total bone marrow cells in a $200-\mu \mathrm{l}$ volume of PBS. Total bone marrow was harvested from two femora into $5 \mathrm{ml}$ KDS/BSS/10\% FCS, counted using trypan blue exclusion, and resuspended at a concentration of $1 \times 10^{7}$ cells $/ \mathrm{ml}$ in PBS. Mice were maintained on $2 \mathrm{mg} / \mathrm{ml}$ neomycin-supplemented water for a minimum period of $21 \mathrm{~d}$.

Immunohistochemistry, TUNEL staining, and image analysis. Tissues were harvested and fixed for 24-48 h in 10\% formalin (for VEGF detection) or formalin-free zinc fixative (for CD31 detection and TUNEL staining; BD). $5-\mu \mathrm{m}$ sections were deparaffinized according to standard histological protocols. For CD31 staining, epitope retrieval was achieved by incubating tissue specimens with $20 \mu \mathrm{g} / \mathrm{ml}$ proteinase $\mathrm{K}$ for $10 \mathrm{~min}$ at $37^{\circ} \mathrm{C}$. For VEGF 
staining, this was achieved by boiling in citrate buffer $(10 \mathrm{mM}$ Na citrate and $0.05 \%$ Tween 20, $\mathrm{pH} 6.0$ ) for $20 \mathrm{~min}$. Antibodies to CD31 (MEC 13.3 at 1/50; BD) or VEGF (Ab-4 at 1/50; EMD) were added for $1 \mathrm{~h}$ at room temperature, and detection was performed using biotinylated polyclonal goat anti-rat IgG antibody (BD) or biotinylated goat anti-rabbit IgG antibody (Jackson ImmunoResearch Laboratories, Inc.) and the ABC detection kit (Vector Laboratories) with diaminobenzidine as the substrate. All photomicrographs were acquired using a $5 \times$ NA 0.15 or $10 \times$ NA 0.3 objective lens attached to a microscope (Axioplan 2; Carl Zeiss). Sequential labeling of

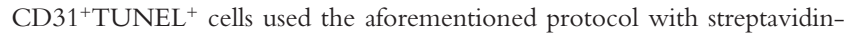
FITC as the secondary detection agent. Sections were then fixed with $4 \%$ paraformaldehyde and permeabilized with $0.2 \%$ Triton X-100 followed by TUNEL staining according to the manufacturer's instructions (Apoptag Red; Millipore). All fluorescence images were acquired using a confocal microscope (CTR MIC; Leica). Microvessel density was calculated by manual counting of a minimum of 10 random independent fields of view using a $40 \times$ objective. The criteria used to identify a microvessel included strong brown (CD31) staining, the presence of a lumen, and more than one $\mathrm{CD} 31^{+}$cell.

Flow cytometric analysis and FACS-Gal assay. Tumors were passed sequentially through a fine mesh metal sieve and 23- and 27-G needles to attain single-cell suspensions that were treated with red cell lysis buffer $\left(5 \mathrm{~min}\right.$ at $4^{\circ} \mathrm{C}$ ) followed by $100 \mu \mathrm{g} / \mathrm{ml}$ DNase I (in BSS and incubated for $5 \mathrm{~min}$ at $37^{\circ} \mathrm{C}$; Roche). An aliquot of the cells was then incubated with $50 \mu \mathrm{l}$ primary antibody for $30 \mathrm{~min}$ at $4^{\circ} \mathrm{C}: 10 \mu \mathrm{g} / \mathrm{ml}$ anti-CD31-APC (MEC 13.3; BD) or, as a control, with rat $\operatorname{IgG}_{2 \mathrm{a}} \mathrm{K}$ coupled to APC (R35-95; BD) in $2 \%$ normal rat serum plus $2.4 \mathrm{G} 2(5 \mu \mathrm{g} / \mathrm{ml}$ anti-Fc $\gamma \mathrm{R}$ mAb) to block $\mathrm{Fc}$ receptors. From 2 to $4 \times 10^{7}$ anti-CD31 antibody-stained cells (in $50 \mu \mathrm{l}$ ) were subjected to FACS-Gal analysis by hypotonic loading with $50 \mu \mathrm{l}$ FDG (fluorescein di- $\beta$-galactopyranoside; Sigma-Aldrich) followed by FACS analysis (Elefanty et al., 1998).

Purification of tumor-associated ECs. Tumor-associated ECs were isolated from homogenized tumor samples using positive magnetic bead selection. In brief, $2 \mu \mathrm{g}$ anti-CD31 $\mathrm{mAb}$ was added per $0.25 \mathrm{~g}$ of tumor (suspended in $2 \mathrm{ml} \mathrm{10 \%} \mathrm{FCS/DME)} \mathrm{and} \mathrm{incubated} \mathrm{at} 4^{\circ} \mathrm{C}$ for $30 \mathrm{~min}$, washed once, and then incubated with $2 \times 10^{7}$ sheep anti-rat IgG antibodycoated magnetic beads (Dynalbeads; Invitrogen). Bead-bound cells were isolated using a magnetic column and washed three times with DME/10\% FCS and once with serum-free DME. For subsequent experiments, cells were released from the beads by incubation with $0.05 \%$ trypsin $/ 0.53 \mathrm{mM}$ EDTA for 5 min at $37^{\circ} \mathrm{C}$.

ELISA to measure VEGF concentration. Tumors snap frozen at $-80^{\circ} \mathrm{C}$ were thawed and passed through a fine mesh sieve before suspension in $5 \mathrm{ml}$ PBS. Samples were subjected to two freeze-thaw cycles, and debris was removed by centrifugation at 13,000 $\mathrm{rpm}$ for $5 \mathrm{~min}$. Total protein levels were determined using the Bradford Assay (Bio-Rad Laboratories), and samples were normalized to 25,50 , and $100 \mu \mathrm{g}$ of total input protein by the addition of assay diluent. VEGF levels were determined using a commercially available ELISA kit (Quantikine MouseVEGF ELISA kit; R\&D Systems) according to the manufacturer's instructions. VEGF concentration was calculated using a standard curve generated by a four-parameter logistic curve fit.

Biochemical analyses. Tumor cell suspensions were washed twice with icecold PBS before lysis in ONYX lysis buffer $(20 \mathrm{mM}$ Tris- $\mathrm{HCl}, \mathrm{pH} 7.4,135 \mathrm{mM}$ $\mathrm{NaCl}, 1.5 \mathrm{mM} \mathrm{MgCl}, 1$ mM EDTA, 1\% Triton X-100, 10\% glycerol, $2 \mathrm{mM} \mathrm{Na}$ orthovanadate, $50 \mathrm{mM}$ Na fluoride, $1 \mu \mathrm{g} / \mathrm{ml}$ pepstatin, $1 \mu \mathrm{g} / \mathrm{ml}$ aprotinin, and $1 \mu \mathrm{g} / \mathrm{ml}$ leupeptin). $25-40 \mu \mathrm{g}$ of total protein per sample was size-fractionated by gel electrophoresis (Tris-glycine Novex Pre-cast gels; Invitrogen) and transferred to nitrocellulose membranes (Hybond-C extra; GE Healthcare). Membranes were probed with antibodies to VEGF (Ab-4; EMD); Bim (Stressgen or Alexis); HSP70 (gift from R. Anderson [Peter MacCallum Cancer Centre]); phosphoErk1/2, phospho-Akt, and total Akt (all from Cell Signaling Technology); and phospho-FOXO3a (Thr 32 specific; Millipore), followed by the relevant horseradish peroxidase-conjugated secondary antibody specific to mouse, rat, or rabbit IgG (Millipore) and visualized using the ECL Western blot detection kit (GE Healthcare).

Dil-Ac-LDL (Dil acetylated low-density lipoprotein) uptake. After magnetic bead-assisted purification, tumor-associated ECs were resuspended in $1 \mathrm{ml}$ serum-free DME supplemented with $10 \mu \mathrm{g} / \mathrm{ml} \mathrm{Ac-LDL}$ (Biomedical Technologies) and incubated at $37^{\circ} \mathrm{C}$ for $4 \mathrm{~h}$. Samples were then washed once and resuspended in $100 \mu \mathrm{l}$ PBS. Cytospins were mounted in aqueous medium containing DAPI and visualized using a confocal microscope (CTR MIC).

Immunohistochemistry, vWF, and F4/80 staining. Tissues were harvested and fixed for $24 \mathrm{~h}$ in $4 \%$ buffered formaldehyde. 5- $\mu \mathrm{m}$ sections were deparaffinized according to standard histological protocols. For vWF staining, epitope retrieval was achieved by incubating tissue specimens with $20 \mu \mathrm{g} / \mathrm{ml}$ proteinase $\mathrm{K}$ for $15 \mathrm{~min}$ at room temperature. This was followed by incubation in $0.2 \mathrm{M}$ glycine $(30 \mathrm{~min})$ to block aldehydes and then by treatment for $30 \mathrm{~min}$ with $10 \%$ hydrogen peroxide in methanol to block endogenous peroxidase. Sections were then washed in PBS and incubated for $2 \mathrm{~h}$ with primary rabbit anti-vWF antibody (Dako) in PBS/1\% BSA containing 5\% normal goat serum (NGS; Vector Laboratories). This staining identifies ECs, megakaryocytes, and platelets. Detection was performed by incubating with biotinylated goat anti-rabbit Ig antibodies (Vector Laboratories) in $\mathrm{PBS} / 1 \% \mathrm{BSA} / 5 \% \mathrm{NGS}$ for $1 \mathrm{~h}$ at room temperature followed by detection with diaminobenzidine as a substrate (ABC detection kit). Sections were reblocked with $\mathrm{PBS} / 1 \% \mathrm{BSA} / 5 \%$ NGS and incubated with rat anti-mouse F4/80 antibody or isotype-matched control antibody overnight at $4^{\circ} \mathrm{C}$. Detection was performed with alkaline phosphatase-conjugated goat anti-rat IgG antibodies (Jackson ImmunoResearch Laboratories, Inc.) and blue alkaline phosphatase substrate (kit III; Vector Laboratories). Sections were counterstained with hematoxylin and mounted with Aqua Poly Mount (Polysciences Inc). All photographs were imaged as for TUNEL and CD31 staining, using a $20 \times$ NA 0.5 objective lens

Flow cytometric analysis of ECs and macrophages. Tumor-derived single-cell suspensions were prepared as described in Flow cytometric analysis and FACS-Gal assay, but with the addition of a collagenase/hyaluronidase digestion step. Cell suspensions were stained with APC-coupled anti-CD31 mAbs (MEC 13.3; BD) or, as a control, with an Ig isotype-matched (IgG2a/ $\mathbf{\kappa}$ ) rat $\mathrm{mAb}$ coupled to APC (R35-95; BD) plus R-PE-conjugated macrophage surface marker-specific mAbs anti-Mac-1 (M1/70) or F4/80 in 2\% normal rat serum plus $2.4 \mathrm{G} 2(5 \mu \mathrm{g} / \mathrm{ml}$ anti-Fc $\gamma \mathrm{R} \mathrm{mAb})$ to block $\mathrm{Fc}_{\mathrm{c}}$ receptors. Cells were washed and resuspended in $10 \%$ FCS $/ \mathrm{PBS}$ plus $1 \mu \mathrm{g} / \mathrm{ml}$ of the vital dye PI and analyzed on an LSR II (BD).

Flow cytometric sorting of tumor cells. Tumor single-cell suspensions were prepared as described in Flow cytometric analysis and FACS-Gal assay and sorted on a cytometer (MoFlo; Beckman Coulter) on the basis of GPF expression: $\mathrm{PI}^{-} \mathrm{GFP}^{+}$(viable tumor cells) and $\mathrm{PI}^{-} \mathrm{GFP}^{-}$(viable nontumor, i.e., stromal cells). Sorted cells were washed, resuspended at $10^{6}$ cells $/ 20 \mathrm{ml}$ in PBS, snap frozen at $-80^{\circ} \mathrm{C}$, and subjected to two freeze-thaw cycles, and debris was removed. Total protein levels were determined using the Bradford assay (Bio-Rad Laboratories), and equal total protein input was used to measure VEGF levels by ELISA.VEGF levels (picograms) were normalized to the secretion from $10^{6}$ cells.

Statistical analysis. For statistical comparison, two-tailed Student's $t$ tests were performed using Prism version 5.0a analysis software (GraphPad Software), with $\mathrm{p}$-values $<0.05$ considered significant.

Online supplemental material. Fig. S1 shows that B16.F1 and 3LL-LLC tumor cell lines stably expressing mutant, hyperactive TK (TK-SR39) are killed by GCV treatment in vitro. Fig. S2 confirms that CD $31^{+}$luminal structures are not macrophages. Fig. $\mathrm{S} 3$ shows that absence of the $\mathrm{BH} 3$-only protein Bmf does not affect the survival of tumor-associated ECs after GCV treatment of B16.F1 melanoma-bearing mice. Fig. S4 shows that GCV-treated 
3LL-LLCs grown in $\mathrm{Bim}^{-/-}$mice contain more viable tumor-associated ECs than GCV-treated tumors grown in WT mice. Fig. S5 provides confirmation of the purity of EC isolates from B16.F1 tumors and shows that the PI3-K-Akt and MAPK-Erk1/2 signaling pathways are modulated in tumorassociated ECs after GCV treatment-induced tumor shrinkage. Fig. S6 shows that Bim deficiency protects tumor-associated ECs from anti-VEGF treatment in a de novo transgenic mouse model of mammary carcinogenesis and provides a model for the multipronged approach to the treatment of solid tumors. Online supplemental material is available at http://www.jem .org/cgi/content/full/jem.20100951/DC1.

We thank Genentech for gifts of anti-VEGF antibodies and Prof. S. Cory and Drs. J. Visvader, G. Lindeman, D.C.S. Huang, J. Kiu, S. Stacker, and B. Helbert for gifts of mutant mice, antibodies, invaluable assistance, and helpful discussions.

This work was supported by grants and fellowships from the Cancer Council of Victoria (to E. Naik and L. Coultas), the National Health and Medical Research Council (Canberra, program \#461221 and fellowships \#461299 [to A. Strasser], \#516703 [to J.M. Adams], and C.J. Martin [to L. Coultas]), the National Institutes of Health (CA43540), the Australian Research Council (to M.-L. Asselin-Labat and D. Merino), and the Leukemia and Lymphoma Society (Specialized Center of Research grant \#7413).

The authors declare no competing financial interests.

Submitted: 12 May 2010

Accepted: 9 May 2011

\section{REFERENCES}

Bergers, G., and L.E. Benjamin. 2003. Tumorigenesis and the angiogenic switch. Nat. Rev. Cancer. 3:401-410. doi:10.1038/nrc1093

Black, M.E., M.S. Kokoris, and P. Sabo. 2001. Herpes simplex virus-1 thymidine kinase mutants created by semi-random sequence mutagenesis improve prodrug-mediated tumor cell killing. Cancer Res. 61:3022-3026.

Bouillet, P., D. Metcalf, D.C.S. Huang, D.M. Tarlinton, T.W.H. Kay, F. Köntgen, J.M. Adams, and A. Strasser. 1999. Proapoptotic Bcl-2 relative Bim required for certain apoptotic responses, leukocyte homeostasis, and to preclude autoimmunity. Science. 286:1735-1738. doi:10.1126/ science.286.5445.1735

Bouillet, P., S. Cory, L.-C. Zhang, A. Strasser, and J.M. Adams. 2001. Degenerative disorders caused by Bcl-2 deficiency prevented by loss of its BH3-only antagonist Bim. Dev. Cell. 1:645-653. doi:10.1016/ S1534-5807(01)00083-1

Cragg, M.S., J. Kuroda, H. Puthalakath, D.C.S. Huang, and A. Strasser. 2007. Gefitinib-induced killing of NSCLC cell lines expressing mutant EGFR requires BIM and can be enhanced by $\mathrm{BH} 3$ mimetics. PLoS Med. 4:e316. doi:10.1371/journal.pmed.0040316

Cragg, M.S., E.S. Jansen, M. Cook, C. Harris, A. Strasser, and C.L. Scott. 2008. Treatment of B-RAF mutant human tumor cells with a MEK inhibitor requires $\mathrm{Bim}$ and is enhanced by a $\mathrm{BH} 3$ mimetic. J. Clin. Invest. 118:3651-3659. doi:10.1172/JCI35437

Cragg, M.S., C. Harris, A. Strasser, and C.L. Scott. 2009. Unleashing the power of inhibitors of oncogenic kinases through BH3 mimetics. Nat. Rev. Cancer. 9:321-326. doi:10.1038/nrc2615

Dhanabal, M., R. Ramchandran, M.J. Waterman, H. Lu, B. Knebelmann, M. Segal, and V.P. Sukhatme. 1999. Endostatin induces endothelial cell apoptosis. J. Biol. Chem. 274:11721-11726. doi:10.1074/jbc.274.17.11721

Dijkers, P.F., R.H. Medema, J.W. Lammers, L. Koenderman, and P.J. Coffer. 2000. Expression of the pro-apoptotic Bcl-2 family member Bim is regulated by the forkhead transcription factor FKHR-L1. Curr. Biol. 10:1201-1204. doi:10.1016/S0960-9822(00)00728-4

Elefanty, A.G., C.G. Begley, D. Metcalf, L. Barnett, F. Köntgen, and L. Robb. 1998. Characterization of hematopoietic progenitor cells that express the transcription factor SCL, using a lacZ "knock-in" strategy. Proc. Natl. Acad. Sci. USA. 95:11897-11902. doi:10.1073/ pnas.95.20.11897
Ellis, L.M., and D.J. Hicklin. 2008. VEGF-targeted therapy: mechanisms of anti-tumour activity. Nat. Rev. Cancer. 8:579-591. doi:10.1038/nrc2403

Ferrara, N., K.A. Houck, L.B. Jakeman, J. Winer, and D.W. Leung. 1991. The vascular endothelial growth factor family of polypeptides. J. Cell. Biochem. 47:211-218. doi:10.1002/jcb.240470305

Ferrara, N., K.J. Hillan, H.P. Gerber, and W. Novotny. 2004. Discovery and development of bevacizumab, an anti-VEGF antibody for treating cancer. Nat. Rev. Drug Discov. 3:391-400. doi:10.1038/nrd1381

Gerber, H.P., V. Dixit, and N. Ferrara. 1998. Vascular endothelial growth factor induces expression of the antiapoptotic proteins $\mathrm{Bcl}-2$ and A1 in vascular endothelial cells. J. Biol. Chem. 273:13313-13316. doi:10.1074/jbc.273.21.13313

Guy, C.T., R.D. Cardiff, and W.J. Muller. 1992. Induction of mammary tumors by expression of polyomavirus middle $\mathrm{T}$ oncogene: a transgenic mouse model for metastatic disease. Mol. Cell. Biol. 12:954-961.

Hasan, J., R. Byers, and G.C. Jayson. 2002. Intra-tumoural microvessel density in human solid tumours. Br. J. Cancer. 86:1566-1577. doi:10.1038/ sj.bjc. 6600315

Kaufmann, T., L. Tai, P.G. Ekert, D.C. Huang, F. Norris, R.K. Lindemann, R.W. Johnstone, V.M. Dixit, and A. Strasser. 2007. The BH3-only protein bid is dispensable for DNA damage- and replicative stressinduced apoptosis or cell-cycle arrest. Cell. 129:423-433. doi:10.1016/ j.cell.2007.03.017

Kokoris, M.S., and M.E. Black. 2002. Characterization of herpes simplex virus type 1 thymidine kinase mutants engineered for improved ganciclovir or acyclovir activity. Protein Sci. 11:2267-2272. doi:10.1110/ps.2460102

Labi, V., M. Erlacher, S. Kiessling, C. Manzl, A. Frenzel, L. O’Reilly, A. Strasser, and A. Villunger. 2008. Loss of the BH3-only protein Bmf impairs B cell homeostasis and accelerates $\gamma$ irradiation-induced thymic lymphoma development. J. Exp. Med. 205:641-655. doi:10.1084/ jem. 20071658

Ley, R., K.E. Ewings, K. Hadfield, and S.J. Cook. 2005. Regulatory phosphorylation of Bim: sorting out the ERK from the JNK. Cell Death Differ. 12:1008-1014. doi:10.1038/sj.cdd.4401688

Liang, W.C., X. Wu, F.V. Peale, C.V. Lee, Y.G. Meng, J. Gutierrez, L. Fu, A.K. Malik, H.P. Gerber, N. Ferrara, and G. Fuh. 2006. Cross-species vascular endothelial growth factor (VEGF)-blocking antibodies completely inhibit the growth of human tumor xenografts and measure the contribution of stromal VEGF. J. Biol. Chem. 281:951-961. doi:10.1074/ jbc.M508199200

Miller, K.D., C.J. Sweeney, and G.W. Sledge Jr. 2001. Redefining the target: chemotherapeutics as antiangiogenics. J. Clin. Oncol. 19:1195-1206.

O’Connor, L., A. Strasser, L.A. O’Reilly, G. Hausmann, J.M. Adams, S. Cory, and D.C.S. Huang. 1998. Bim: a novel member of the Bcl-2 family that promotes apoptosis. EMBO J. 17:384-395. doi:10.1093/ emboj/17.2.384

O'Reilly, L.A., L. Cullen, J. Visvader, G.J. Lindeman, C. Print, M.L. Bath, D.C.S. Huang, and A. Strasser. 2000. The proapoptotic BH3-only protein bim is expressed in hematopoietic, epithelial, neuronal, and germ cells. Am. J. Pathol. 157:449-461. doi:10.1016/S0002-9440(10)64557-9

Oltersdorf, T., S.W. Elmore, A.R. Shoemaker, R.C. Armstrong, D.J. Augeri, B.A. Belli, M. Bruncko, T.L. Deckwerth, J. Dinges, P.J. Hajduk, et al. 2005. An inhibitor of Bcl-2 family proteins induces regression of solid tumours. Nature. 435:677-681. doi:10.1038/nature03579

Park, Y.W., M.N. Younes, S.A. Jasser, O.G. Yigitbasi, G. Zhou, C.D. Bucana, B.N. Bekele, and J.N. Myers. 2005. AEE788, a dual tyrosine kinase receptor inhibitor, induces endothelial cell apoptosis in human cutaneous squamous cell carcinoma xenografts in nude mice. Clin. Cancer Res. 11:1963-1973. doi:10.1158/1078-0432.CCR-04-1665

Villunger, A., E.M. Michalak, L. Coultas, F. Müllauer, G. Böck, M.J. Ausserlechner, J.M. Adams, and A. Strasser. 2003. p53- and druginduced apoptotic responses mediated by $\mathrm{BH}$-only proteins puma and noxa. Science. 302:1036-1038. doi:10.1126/science.1090072

Youle, R.J., and A. Strasser. 2008. The BCL-2 protein family: opposing activities that mediate cell death. Nat. Rev. Mol. Cell Biol. 9:47-59. doi: $10.1038 / \mathrm{nrm} 2308$ 


\section{University Library}

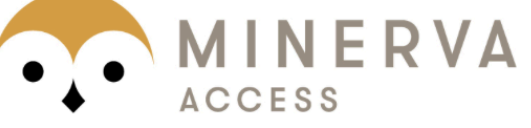

A gateway to Melbourne's research publications

Minerva Access is the Institutional Repository of The University of Melbourne

Author/s:

Naik, E;O'Reilly, LA;Asselin-Labat, M-L;Merino, D;Lin, A;Cook, M;Coultas, L;Bouillet, $\mathrm{P} ;$ Adams, JM;Strasser, A

Title:

Destruction of tumor vasculature and abated tumor growth upon VEGF blockade is driven by proapoptotic protein Bim in endothelial cells

Date:

2011-07-04

Citation:

Naik, E., O'Reilly, L. A., Asselin-Labat, M. -L., Merino, D., Lin, A., Cook, M., Coultas, L., Bouillet, P., Adams, J. M. \& Strasser, A. (2011). Destruction of tumor vasculature and abated tumor growth upon VEGF blockade is driven by proapoptotic protein Bim in endothelial cells. JOURNAL OF EXPERIMENTAL MEDICINE, 208 (7), pp.1351-1358. https:// doi.org/10.1084/jem.20100951.

Persistent Link:

http://hdl.handle.net/11343/264770

License:

CC BY-NC-SA 